\title{
Nonspecific blockade of vascular free radical signals by methylated arginine analogues
}

\section{M.A. Pedro ${ }^{1}$, O. Augusto', H.V. Barbeiro', M.H.C. Carvalho', P.L. da-Luz ${ }^{3}$ and F.R.M. Laurindo 3}

\author{
1Departamento de Bioquímica, Instituto de Química, \\ 2Departamento de Farmacologia, Instituto de Ciências Biomédicas, and \\ ${ }^{3}$ Instituto do Coração, Faculdade de Medicina, Universidade de São Paulo, \\ São Paulo, SP, Brasil
}

Correspondence
F.R.M. Laurindo
Instituto do Coração
Faculdade de Medicina, USP
Av. Eneas C. Aguiar, 44, Subsolo
05403-000 São Paulo, SP
Brasil
Fax: 55 (011) 282-2354
Research supported by FAPESP,
CNPq, FINEP and Fundação E.J.
Zerbini.
. . . . . . . . . . . . . . . . . . . . . . .

Received July 11, 1997 Accepted March 18, 1998

\section{Abstract}

Methylated arginine analogues are often used as probes of the effect of nitric oxide; however, their specificity is unclear and seems to be frequently overestimated. This study analyzed the effects of $\mathrm{N}^{\mathrm{G}}$ methyl-L-arginine (L-NMMA) on the endothelium-dependent release of vascular superoxide radicals triggered by increased flow. Plasma ascorbyl radical signals measured by direct electron paramagnetic resonance spectroscopy in 25 rabbits increased by $3.8 \pm 0.7 \mathrm{nmol} / 1 \mathrm{vs}$ baseline $(28.7 \pm 1.4 \mathrm{nmol} / \mathrm{l}, \mathrm{P}<0.001)$ in response to papaverineinduced flow increases of $121 \pm 12 \%$. In contrast, after similar papaverine-induced flow increases simultaneously with L-NMMA infusions, ascorbyl levels were not significantly changed compared to baseline. Similar results were obtained in isolated rabbit aortas perfused ex vivo with the spin trap $\alpha$-phenyl-N-tert-butylnitrone $(\mathrm{N}=22)$. However, in both preparations, this complete blockade was not reversed by co-infusion of excess L-arginine and was also obtained by $\mathrm{N}$-methyl-D-arginine, thus indicating that it is not related to nitric oxide synthase. L-arginine alone was ineffective, as previously demonstrated for $\mathrm{N}^{\mathrm{G}}$-methyl-L-arginine ester (L-NAME). In vitro, neither L-arginine nor its analogues scavenged superoxide radicals. This nonspecific activity of methylated arginine analogues underscores the need for careful controls in order to assess nitric oxide effects, particularly those related to interactions with active oxygen species.

\section{Introduction}

L-arginine analogues have been widely used as probes for the investigation of the effects of nitric oxide in a variety of in vitro and in vivo systems. Their established efficacy as nitric oxide synthase inhibitors has undoubtedly made a significant contribution to the understanding of nitric oxide biology $(1,2)$ and may eventually have a clinical
Key words - Free radicals

- Arginine analogues

- NG-methyl-L-arginine

- $N^{G}$-methyl-D-arginine

- $N^{G}$-nitro-L-arginine methyl ester 
cific actions has been described (3-8), circumstantial evidence suggests that researchers in the area may significantly overestimate the specificity of L-arginine analogues. Recently, our laboratory reported data suggesting that increases in shear stress trigger the release of free radicals from the endothelium (9). These data were assessed by electron paramagnetic resonance (EPR) spectroscopic techniques, both ex vivo by measurement of radical adducts with spin traps and in vivo by direct measurements of plasma ascorbyl radical. In both cases, the increase in EPR signals was abolished by superoxide dismutase, suggesting that either the change in spin adduct or ascorbyl signals reflect the generation of superoxide radicals.

The purpose of the present study is to report the nonspecific blocking effect of methylated arginine analogues on flow-related free radical production observed with the use of the above EPR techniques and to call attention to other similar reported effects. These results may help clarify the interpretation of data on the putative biological roles of nitric oxide, particularly those related to its interaction with reactive oxygen species $(10,11)$.

\section{Material and Methods}

Papaverine hydrochloride was obtained from the hospital pharmacy. Human recombinant $\mathrm{CuZn-SOD}$ was a kind gift of Dr. Pablo Valenzuela, Chiron Corp. (Emeryville, CA). All other compounds were from Sigma Chemical Co. (St. Louis, MO). L-NMMA and D-NMMA were used as acetate salts. LNMMA acetate from Wellcome (the kind gift of Prof. Salvador Moncada) was also used. PBN ( $\alpha$-phenyl-N-tert-butylnitrone) was recrystallized from hexane.

\section{In vivoascorbyl radical measurements}

The rabbit preparation used to assess plasma ascorbyl radical levels in response to iliac flow increases was described previously (9). Briefly, 25 male New Zealand white rabbits weighing 2.4 to $3.1 \mathrm{~kg}$ were anesthetized with sodium pentobarbital and instrumented with an electromagnetic flow probe at the origin of the right iliac artery. Rapid, transient and reproducible increases in blood flow were induced by bolus injections of papaverine ( 2 to $5 \mathrm{mg}$ ) delivered by a catheter advanced through the left femoral artery up to 0.5 to $1 \mathrm{~cm}$ above the iliac bifurcation. A short polyethylene catheter was advanced through a right femoral branch for blood collection at baseline, at maximal flow, and $15 \mathrm{~min}$ after papaverine injection. Systemic arterial pressure was continuously recorded from the left carotid artery. All rabbits were submitted to a first control papaverine bolus followed by a second one, simultaneously with a $3.8 \mathrm{ml} / \mathrm{min}$ infusion of $0.9 \% \mathrm{NaCl}, \mathrm{L}$-arginine or its methylated analogues. The infusion was started $20 \mathrm{~min}$ after the first papaverine bolus at the initial rate of $1.0 \mathrm{ml} / \mathrm{min}$; after $75 \%$ of the total volume was given, the second papaverine challenge was performed, and the infusion was terminated 1-2 min thereafter. Plasma ascorbyl levels were assessed by direct EPR spectroscopy as described (9).

\section{Ex vivoaortic perfusion with PBN}

The preparation of thoracic aortas from 27 other rabbits was also described previously (9). Briefly, rabbits were killed with pentobarbital and their thoracic aortas placed in a closed perfusion chamber $(7.0 \times 0.8 \mathrm{~cm})$ connected on both sides to a closed tubing circuit with an open reservoir. Flow was provided in the physiological arterial direction by a roller pump without changing the perfusion pressure, even with increased flow. The system was primed with $6.0 \mathrm{ml}$ of oxygenated Krebs-Henseleit solution at $37^{\circ} \mathrm{C}$ (9). The lipophilic spin-trap PBN (20 mM) was added immediately before starting arterial perfusion. In control experiments, 
no L-arginine analogues were added; flow rate was started at $2 \mathrm{ml} / \mathrm{min}$ and maintained for $10 \mathrm{~min}$. The first aortic fragment was then collected in liquid nitrogen. In the remainder of the vessel, the flow rate was increased to $12 \mathrm{ml} / \mathrm{min}$ for another 10 min and the fragment was then frozen. The same procedures were followed in other perfused aortas after the addition of methylated L-arginine analogues to the perfusate. Lipid extracts of arterial fragment homogenates were analyzed for PBN radical adducts, which were quantified by double integration of their EPR signals using TEMPOL (4-hydroxy2,2,6,6-tetramethylpiperidine- $N$-oxyl) as a standard.

\section{Superoxide radical production in vitroassay}

The scavenger activity of arginine or its analogues was tested in vitro by the method of McCord and Fridovich (12) using xanthine/xanthine oxidase as the source of superoxide. Briefly, the reaction mixture contained $10 \mu \mathrm{M}$ ferricytochrome c, $50 \mu \mathrm{M}$ xanthine, and sufficient xanthine oxidase (about $6 \mathrm{nM}$ ) to produce a rate of reduction of ferricytochrome $\mathrm{c}$ at $550 \mathrm{~nm}$ of 0.030 absorbance units per min. Human recombinant SOD, with $16986 \mathrm{U} / \mathrm{mg}$ of protein, was used as standard for superoxide radical inhibition after the specified dilutions. L-NMMA, D-NMMA, L-NAME, or L-arginine was added to the system without SOD, each at $1.0 \mathrm{mM}$ final concentration.

\section{Statistical analysis}

Data are reported as means $\pm \mathrm{SEM}$. Parameter changes $v s$ baseline were analyzed by the paired $t$-test. Intergroup comparisons were tested by one-way ANOVA and the Student-Newman-Keuls multiple range test. The significance level was $\mathrm{P}<0.05$. The Primer of Biostatistics computer program (by S.A. Glantz, McGraw Hill, 1992) was used.

\section{Results}

\section{Effects of methylated L-arginine analogues on in vivo flow-dependent vascular free radical release}

All pairwise control papaverine injections performed in each rabbit before the treatments with methylated L-arginine analogues were pooled to simplify data treatment $(\mathrm{N}=25)$, since blood flow and ascorbyl radical changes were similar for all groups for this control condition. An intra-arterial bolus injection of papaverine (2 to $5 \mathrm{mg}$ ) caused an increase in right iliac flow of 121 $\pm 12 \%$ vs baseline levels of $16.0 \pm 1.2 \mathrm{ml} /$ min, which was accompanied by an increase in the ascorbyl radical levels of $3.8 \pm 0.7$ $\mathrm{nmol} / \mathrm{l} v \mathrm{~s}$ baseline values of $28.7 \pm 1.4 \mathrm{nmol} /$ 1 for the control group. Baseline values for the other groups were as follows: L-NMMA $(31.9 \pm 1.7 \mathrm{nmol} / \mathrm{l}), \mathrm{D}-\mathrm{NMMA}(28.9 \pm 2.2$ nmol/l), L-arginine + L-NMMA (23.6 \pm 1.8 $\mathrm{nmol} / \mathrm{l})$, and L-arginine $(29.8 \pm 2.8 \mathrm{nmol} / \mathrm{l})$; none of these values was significantly different from the control group or each other. By 15 min after papaverine injection, ascorbyl radical levels had already returned toward baseline values, accompanying the normalization of blood flow. Figure 1 illustrates representative ascorbyl radical spectra and Figure 2 depicts the overall absolute change in plasma ascorbyl levels accompanying papaverine-induced flow changes during treatment with L-NMMA (10 mg/kg; $\mathrm{N}=6)$, DNMMA (10 mg/kg; $\mathrm{N}=6)$, L-arginine + LNMMA $(100 \mathrm{mg} / \mathrm{kg}$ and $10 \mathrm{mg} / \mathrm{kg}$, respectively; $\mathrm{N}=5)$ and L-arginine $(100 \mathrm{mg} / \mathrm{kg} ; \mathrm{N}$ $=3$ ). L-NMMA, D-NMMA and L-arginine + L-NMMA did not induce significant changes in flow by themselves. L-arginine, at the dose of $100 \mathrm{mg} / \mathrm{kg}$, significantly increased baseline flow from $21.3 \pm 1.5$ to $31.3 \pm 2.8$ $\mathrm{ml} / \mathrm{min}(\mathrm{P}<0.02)$. L-NMMA completely blocked flow-induced production of ascorbyl free radicals. This effect was shared with D-NMMA and was not reversed by excess 
L-arginine (Figures 1 and 2).

Treatment with L-NMMA induced a sustained increase in arterial pressure from 108.8 \pm 4.3 to $117.0 \pm 3.1 \mathrm{mmHg}(\mathrm{P}<0.05)$, while D-NMMA and L-arginine did not induce significant changes. The co-infusion of Larginine and L-NMMA completely prevented the increase in arterial pressure. The peak percent decrease in arterial pressure with papaverine after each of those treatments was similar to that observed before any treatment. None of these interventions induced significant changes in baseline ascorbyl radical levels, except for L-arginine, which
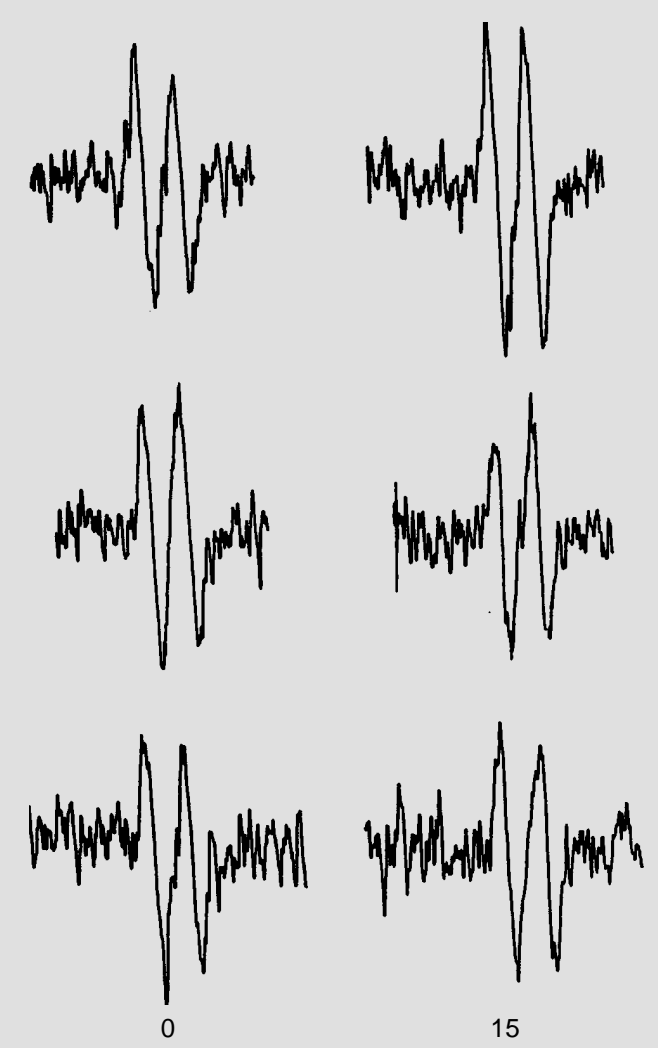

15

Time (s)

Figure 1 - Characteristic electron paramagnetic resonance spectra of arterial plasma ascorbyl radical (hyperfine splitting constant, $a_{H}=0.186 \mathrm{mT}$ ) and its change in response to a flow increase induced by intra-arterial papaverine $(2 \mathrm{mg})$ in untreated control animals. The increase in ascorbyl signals was completely abolished in rabbits treated with L-NMMA and D-NMMA. Peak flow increases occurred at $15 \mathrm{~s}$ and returned to baseline levels by $120 \mathrm{~s}$ after papaverine injection. Data acquisition parameters were as follows: potency, $20 \mathrm{~mW}$; frequency, $9.7 \mathrm{GHz}$; modulation amplitude, $0.1 \mathrm{mT}$; sweeping velocity $0.01 \mathrm{mT} / \mathrm{s}$; time constant, $1000 \mathrm{~ms}$. caused a significant increase of $4.1 \pm 0.9$ $\mathrm{nmol} / \mathrm{l}(\mathrm{P}<0.05)$ in plasma ascorbyl levels from pretreatment values. L-lysine $(100 \mathrm{mg} /$ $\mathrm{kg}$ ), a positively charged amino acid (as is Larginine), induced no change in papaverineinduced blood flow or ascorbyl increases.

\section{Ex vivoaortic perfusion and detection of PBN radical adducts}

The effects of each treatment with Larginine analogues on the flow-induced change in PBN radical adduct yields are shown in Figure 3. In control experiments ( $N$ $=11$ ) the changes in perfusion rate from 2 to $12 \mathrm{ml} / \mathrm{min}$ were accompanied by increases of PBN adduct levels from $3.2 \pm 0.9$ to $7.0 \pm$ $1.5 \mathrm{pmol} / \mathrm{mg}(\mathrm{P}<0.005)$. Both L-NMMA $(0.1$ $\mathrm{mM} ; \mathrm{N}=4)$ and D-NMMA (0.1 mM; $\mathrm{N}=4)$ completely inhibited free radical production, an effect not overcome by the coincubation of excess L-arginine with L-NMMA (1.0 $\mathrm{mM}$ and $0.1 \mathrm{mM}$, respectively; $\mathrm{N}=3$ ).

\section{Effects of L-arginine and its analogues on superoxide radical production in vitro}

The rate of ferricytochrome $\mathrm{c}$ reduction detected at $550 \mathrm{~nm}$ was $2.1 \mu \mathrm{M} / \mathrm{min}$, with $\varepsilon_{550}=15300 \mathrm{M}^{-1} \mathrm{~cm}^{-1}$. In our previous study with isolated rabbit aortas, the dose of SOD that effectively abolished the increase in PBN radical adduct signal was $100 \mu \mathrm{g} / \mathrm{ml}$. This concentration completely inhibited superoxide production in the present assay. Further dilutions were then tested, so that at the final concentration of $2.5 \mathrm{fg} / \mathrm{ml}$ (thus, a dilution of $\approx 10^{8}$ times), SOD inhibited superoxide production by $32.8 \%$. In contrast, L-NMMA, DNMMA, L-NAME and L-arginine at $1.0 \mathrm{mM}$ final concentration showed only negligible superoxide inhibition, with respective average values of $4.1,7.1,6.1$ and $10.0 \%$. Therefore, it is unlikely that methylated arginine analogues directly scavenged significant amounts of superoxide radicals in the present conditions. 


\section{Discussion}

The present study reports the blocking effect of methylated arginine analogues on the release of free radicals triggered by increases in shear stress. This blocking effect was probably independent of nitric oxide synthase activity since it was not reversed by excess L-arginine and was shared by both the L- and D-isomers. Our previous work (9) showed that the flow-dependent increase in free radical signals was completely abolished by removal of the endothelium or by native superoxide dismutase and those signals were unchanged by catalase, indomethacin or L-NAME. Thus, the observed signal increases were probably due to superoxide radicals released extracellularly through an endothelium-dependent mechanism not involving cyclooxygenase or nitric oxide synthase activities. In addition, the reaction between nitric oxide and spin traps or ascorbate is quite unlikely to occur under those conditions $(9,13,14)$, another argument against a role for nitric oxide in flow-triggered radical signals.

Several mechanisms mightexplain the present findings. It is unlikely that L-arginine analogues acted as nonspecific blockers of the flow transduction signaling cascade, since a number of previous studies showed that LNMMA, even at a dose of $200 \mathrm{mg} / \mathrm{kg}$, had no effect on flow-mediated vasodilation (15-17). It is also unlikely that those compounds directly scavenged superoxide radicals, since our experiments showed no in vitro scavenger activity of L-arginine or its analogues. Furthermore, our observations appear to be unrelated to the known differential effects of L-arginine analogues on superoxide generation from nitric oxide synthase. In this case, L-NAME as well as L-arginine, but not L-NMMA, completely blocked superoxide generation in vitro (18). In addition, in cultured endothelial cells exposed to low-density lipoproteins, such uncoupling of L-arginine uptake from nitric oxide synthesis was also prevented by L-NAME

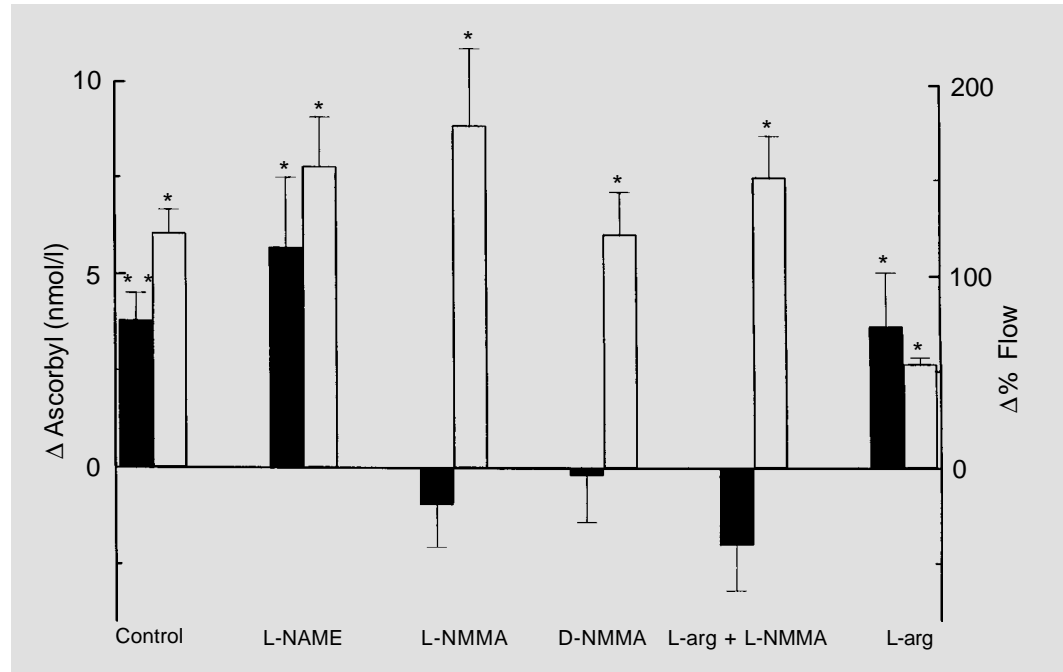

Figure 2 - The effects of several treatments on papaverine-induced increases in flow (open bars) and arterial plasma ascorbyl radical levels (closed bars). A pairwise control papaverine injection was performed in each rabbit before starting the treatments; however, since blood flow and ascorbyl radical changes were similar for all treatment groups for this control condition, the results were pooled for simplification (Control; $N=25)$. Neither L-NMMA ( $N=$ 6) nor D-NMMA $(\mathrm{N}=6)$ altered papaverine-induced flow changes, but they both completely abolished the corresponding ascorbyl radical increase. Excess $L$-arginine coinfusion with $L-$ NMMA (L-arg + L-NMMA; N = 5) did not overcome the blockade in ascorbyl increase. Larginine ( $L$-arg; $N=3$ ) alone diminished papaverine-induced flow changes $(P<0.05$ vs other treatments), but did not impair ascorbyl radical increases. Data with L-NAME were previously published (9) and are shown only for comparison. ${ }^{*} \mathrm{P}<0.001$, and ${ }^{*} \mathrm{P}<0.05$ vs baseline, respectively (ANOVA and Student-Newman-Keuls multiple range test). Data are reported as means \pm SEM.

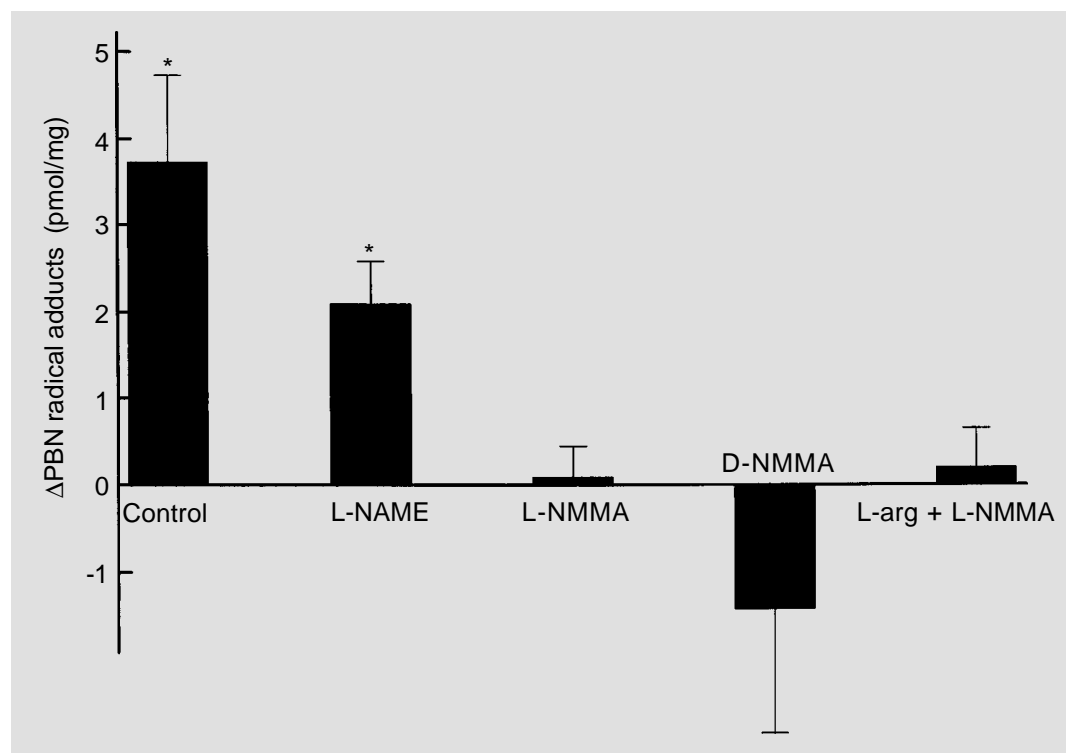

Figure 3 - Flow-related increases in $\alpha$-phenyl- $N$-tert-butylnitrone (PBN) radical adduct yields in endothelialized aortas in the control (Control) condition and after treatment with L-NMMA $(\mathrm{N}=4)$, D-NMMA $(\mathrm{N}=4)$ and L-arginine + L-NMMA $(\mathrm{N}=3)$. Data with L-NAME $(\mathrm{N}=5)$ were previously published (9) and are shown only for comparison. Both L-NMMA and D-NMMA completely blocked radical generation. L-arginine did not reverse the blockade. ${ }^{*} \mathrm{P}<0.02 \mathrm{vs}$ baseline. The SNK multiple range test showed that the control group was different from all groups, except for L-NAME. The D-NMMA group did not differ from the L-NMMA or L-arg + L-NMMA group. Data are reported as means \pm SEM. 
or L-arginine (19), in contrast to our data. The most likely mechanism for the arginine analogue effect involves their interaction with species derived from the flow-triggered radical (probably superoxide). These species are not exclusive blood or plasma constituents, since the blocking effect was observed in vitro as well as in vivo. One possibility is that catalytic metal complexes are involved in these processes. Peterson et al. (4) reported that Land D-arginine analogues can complex with iron in vitro in such a way that NMMA and NAME exhibit different effects. Those nonspecific iron-chelating properties may inhibit cyclo- or lipoxygenases in vivo (20). In addition, L-NMMA was shown to attenuate copper-induced LDL oxidation in vitro (8). Interestingly, the metal chelators deferoxamine or 1,10 phenanthroline completely blocked flowdependent free radical release in vitro or in vivo (data not shown), thus suggesting that redox active metals participate in this phenomenon, probably as secondary reactants.

The present findings add to other reports of nonspecific actions of L-arginine analogues. Some examples include the muscarinic receptor blocking effect of L-NAME (but not L-NMMA) (6), the decrease in Larginine uptake by L-NMMA (but not LNAME) (3) and antagonism of endothelium and nitric oxide-independent vasodilation due to amiloride or dibutyril cyclic AMP by LNMMA (5). In pial arterioles, the vasoconstriction induced by L-NMMA or nitro-Larginine may be due to cyclooxygenase-dependent superoxide production rather than nitric oxide synthase blockade (7). The different isoenzyme blocking profiles of methylated, as compared to nitrated, analogues are further consistent with other effects beyond nitric oxide synthase inhibition, although some peculiarities may be due to pharmacokinetic properties, e.g., the relative lipophilicity of L-NAME. In particular, L-NMMA exhibits a potent blocking effect of the macrophage isoenzyme, with characteristics of irreversibility (21), whereas ni-
tro-L-arginine induces only a mild reversible blockade of the macrophage isoenzyme, but has a potent irreversible effect upon the brain isoenzyme (22). Finally, it should be noted that nitric oxide synthase is a mixed-function oxidase; thus, in some cases, documenting its enzymatic activity does not imply that the effect is mediated by nitric oxide (23). When nitric oxide levels were measured together with the arginine analogue effects, some significant unexpected discrepancies were reported (24).

Our data, as well as the observations discussed above, underscore the importance of adequate controls for the evaluation of the biological roles of nitric oxide. On the basis of these data, we propose that the use of Larginine analogues as probes of nitric oxide synthase activity should be controlled by at least 3 of the 4 following procedures: 1) reversal of the observed analogue effects by excess L-arginine; 2) if L-arginine reverses the blockade, it should be proved that Darginine does not reverse it; 3) observation of the effects of the D-analogue form; 4) observation of the effects of more than one blocking analogue. In addition, data should be preferably complemented with measurements of nitric oxide synthase activity or nitric oxide levels. In particular, our data document the role of procedures 3 and 4 (use of the D-analogues and use of more than one antagonist), which are simple, but rarely performed. These procedures should be particularly considered when evaluating the vascular interactions of nitric oxide with reactive oxygen species, or when assessing putative cytotoxic or cytostatic effects of nitric oxide.

\section{Acknowledgments}

The authors are grateful to Maria Antonietta da Silva Leitão, Instituto de Química, Universidade de São Paulo, for help with the in vitro superoxide production assay. 


\section{References}

1. Moncada S \& Higgs A (1993). The L arginine-nitric oxide pathway. New England Journal of Medicine, 329: 2002-2012.

2. Loscalzo J \& Welch R (1995). Nitric oxide and its roles in the cardiovascular system. Progress in Cardiovascular Diseases, 37: 87-104.

3. Bogle RG, Moncada S, Pearson JD \& Mann GE (1992). Identification of inhibitors of nitric oxide synthase that do not interact with the endothelial cell L-arginine transporter. British Journal of Pharmacology, 105: 768-770.

4. Peterson DA, Peterson DC, Archer S \& Weir EK (1992). The non-specificity of specific nitric oxide synthase inhibitors. Biochemical and Biophysical Research Communications, 187: 797-801.

5. Thomas G \& Ramwell PW (1992). Interaction of non arginine compounds with the endothelium-derived relaxing factor inhibitor, NG monomethyl-L-arginine. Journal of Pharmacology and Experimental Therapeutics, 260: 676-679.

6. Buxton ILO, Cheek DJ, Eckman D, Westfall DP, Sanders KM \& Keef KD (1993). $N^{G}$-nitro-L-arginine methyl ester and other alkyl esters of arginine are muscarinic receptor antagonists. Circulation Research, 72: 387-395.

7. Rosenblum WI, Nishimura $\mathrm{H}$ \& Nelson GH (1992). L-NMMA in brain microcirculation is inhibited by blockade of cyclooxygenase and by superoxide dismutase. American Journal of Physiology, 262: H1343-H1349.

8. Jessup W \& Dean RT (1993). The antioxidant properties of an inhibitor of nitric oxide synthase. Free Radical Biology and Medicine, 14: 447-448.

9. Laurindo FRM, Pedro MA, Barbeiro HV,
Pileggi F, Carvalho MHC, Augusto O \& da Luz PL (1994). Vascular free radical release; ex vivo and in vivo evidence for a flow-dependent endothelial mechanism. Circulation Research, 74: 700-709.

10. Laurindo FRM, da Luz PL \& Augusto $O$ (1995). Potential roles of oxygen-derived free radicals in vascular function. In: Davies KJM \& Ursini F (Editors), The Oxygen Paradox. CLEUP Press, Padova, 235245.

11. Darley-Usmar V, Wiseman $\mathrm{H}$ \& Halliwell $B$ (1995). Nitric oxide and oxygen radicals: a question of balance. FEBS Letters, 369: 131-135.

12. McCord JM \& Fridovich I (1969). Superoxide dismutase. An enzymic function for erythrocuprein (hemocuprein). Journal of Biological Chemistry, 244: 6049-6055.

13. Carmichael AJ, Steel-Goodwin L, Gray B \& Arroyo CM (1993). Reactions of active oxygen and nitrogen species studied by EPR and spin trapping. Free Radical Research Communications, 19 (Suppl): S1S16.

14. Mehlhorn RJ (1991). Ascorbate and dehydroascorbic acid-mediated reduction of free radicals in the human erythrocyte. Journal of Biological Chemistry, 266: 2724-2731.

15. Fuji K, Heistad DD \& Faraci FM (1991). Flow-mediated dilatation of the basilar artery in vivo. Circulation Research, 69: 697705.

16. Koller AD, Sun D \& Kailey G (1993). Role of shear stress and endothelial prostaglandins in flow and viscosity-induced dilation of arterioles in vitro. Circulation Research, 72: 1276-1284.

17. Melkumyants AM, Balashov SA, Klimachev AN, Kartamychev SP \&
Khayutin VM (1992). Nitric oxide does not mediate flow-induced endothelium-dependent arterial dilatation in the cat. Cardiovascular Research, 26: 256-260.

18. Pou S, Pou WS, Bredt DS, Snyder SH \& Rosen GM (1992). Generation of superoxide by purified brain nitric oxide synthase. Journal of Biological Chemistry, 267: 24173-24176.

19. Pritchard Jr KA, Groszek L, Smalley DM, Sessa WC, Wu M, Villalon P, Wolin MS \& Stemerman MB (1995). Native low-density lipoprotein increases endothelial cell nitric oxide synthase generation of superoxide anion. Circulation Research, 77: 510-518.

20. Martin EB, Leis LA, Peterson DA, Johnson GJ \& Archer SL (1995). Altered platelet aggregation due to chronic exposure to a nitric oxide synthase inhibitor. Circulation, 92 (Suppl I): I-566 (Abstract).

21. Olken NM, Rusche KM, Richards MK \& Marletta MA (1991). Inactivation of macrophage nitric oxide synthase by $\mathrm{NG}^{\mathrm{G}}$-methyl-L-arginine. Biochemical and Biophysical Research Communications, 177: 828-833.

22. Dwyer MA, Bredt DS \& Snyder SH (1991). Nitric oxide synthase: irreversible inhibition by $\mathrm{L}-\mathrm{NG}$-nitroarginine in brain in vitro and in vivo. Biochemical and Biophysical Research Communications, 176: 11361141.

23. Klatt $P$, Schmidt $K$, Uray $G$ \& Mayers $B$ (1993). Multiple catalytic functions of brain nitric oxide synthase. Journal of Biological Chemistry, 268: 14781-14787.

24. Archer SL \& Hampl V (1992). NG-monomethyl-L-arginine causes nitric oxide synthesis in isolated arterial rings: trouble in paradise. Biochemical and Biophysical Research Communications, 188: 590-596. 